\title{
COLLIMATOR EXCHANGE EFFECT OF MEGAVOLTAGE PHOTON BEAMS AND ITS IMPACT ON CLINICAL DOSIMETRY
}

\section{Shachindra Goswami}

Bhaveshwar Yadav

\section{Shashi Bhushan Sharma}

Mithu Barthakur

\section{Pranjal Goswami}

\section{Gautam Sarma*}

Sr. Medical Physicist, Department of Radiation Oncology, Dr. B. Borooah Cancer Institute, Guwahati, India

Medical Physicist, Department of Radiation Oncology, Dr. B. Borooah Cancer Institute, Guwahati, India

Medical Physicist, Department of Radiation Oncology, Dr. B. Borooah Cancer Institute, Guwahati, India

Sr. Medical Physicist, Department of Radiation Oncology, Dr. B. Borooah Cancer Institute, Guwahati, India

Sr. Medical Physicist, Department of Radiation Oncology, Dr. B. Borooah Cancer Institute, Guwahati, India

Assistant Professor, Department of Radiation Oncology, Dr. B. Borooah Cancer Institute, Guwahati, India. ${ }^{*}$ Corresponding Author

ABSTRACT AIM: To determine the Collimator Exchange Effect (CEE) for telecobalt unit (Bhabhatron -II TAW) and Linear accelerator unit (Varian Trilogy).

MATERIALS AND METHOD: The study was carried out in Bhabhatron-II TAW Telecobalt machine and Varian Trilogy Linear Accelerator. The study was done to find the collimator scatter factor (Sc) for rectangular fields at 5 and $10 \mathrm{gm} / \mathrm{cm} 2 \mathrm{depths} \mathrm{using}$ indigenously designed mini phantom. Three sets of electrometer reading were noted for the irradiation of each field size and the average was taken for calculation. Sc values for different rectangular fields were then calculated from these data sets and the CEE at two depths ( 5 and $10 \mathrm{gm} / \mathrm{cm} 2$ ) for the 6MV and 15MV photon and Co-60 gamma beam were calculated.

RESULTS:The values of Sc obtained for the rectangular fields as alternatively defined by X \& Y jaws are different for high energy photon beams indicating CEE. The maximum percentage difference between the $\mathrm{Sc}$ of the corresponding collimator settings for the Bhabhatron-II TAW unit for depths 5 and $10 \mathrm{gm} / \mathrm{cm} 2$ were found to be $0.42 \%$ and $0.5 \%$ respectively. Sc values for $6 \mathrm{MV}$ and $15 \mathrm{MV}$ photon beams were found to be higher when Y-jaw (upper jaw) acts as the longer side of the rectangular field. The maximum percentage difference between the Sc values of the corresponding collimator settings for 6MV at depths 5 and $10 \mathrm{gm} / \mathrm{cm} 2$ were $2.74 \%$ and $2.87 \%$ respectively whereas for $15 \mathrm{MV}$ the differences were $3 \%$ and $2.99 \%$.

CONCLUSION:The CEE of Cobalt Teletherapy units can be ignored in clinical dosimetry. However, the CEE of Linear Accelerators having energies 6MV \& 15MV should be taken into consideration. A two dimensional table of Sc should be generated for rectangular fields during MU calculations in Linear Accelerators. For TPS based calculations, the generated data should be incorporated during beam modeling for accurate dose delivery in clinical dosimetry.

KEYWORDS : Collimator Exchange Effect, Bhabhatron-II TAW, Varian Trilogy, Mini-phantom

INTRODUCTION:

The effective radiation dose used in treatment of cancer is measured from the output factors generated from megavoltage teletherapy machines under reference conditions. It can be expressed as the sum of two componentsprimary dose and scattered dose. The output factor is the total scatter correction factor $\left(\mathrm{S}_{\mathrm{c}, \mathrm{p}}\right)$ at $\mathrm{d}_{\max } \cdot{ }^{[1]}$ Holt et al and subsequently several other authors used the concept of separation of the total scatter correction factor $\left(\mathrm{S}_{\mathrm{c}, \mathrm{p}}\right)$ into collimator scatter factor $\left(\mathrm{S}_{\mathrm{c}}\right)$ and phantom scatter factor $\left(\mathrm{S}_{\mathrm{p}}\right)$. $^{[1-5]}$ For rectangular fields, the interchange of upper and lower collimator jaws causes variation in the collimator scatter factor which is commonly termed as the Collimator Exchange Effect (CEE). ${ }^{[6-13]}$ This effect is due to $(\alpha)$ the photons scattered from the flattening filter reaching to the point of measurement and (b) photons scattered backward from the upper and lower collimator jaws into the beam monitor chamber. ${ }^{[7,12,13,14]}$ The magnitude of $\mathrm{CEE}$, therefore depends on the configuration of the head of the treatment machine including factors such as the dimensions and material of the flattening filter, the distance between the upper collimator parts and the monitor chamber, and the presence of shielding material in the accelerator head. Megavoltage teletherapy machines have different treatment head design and hence are expected to show different CEE values. ${ }^{[15]}$

During radiation therapy of patients, different field sizes and shapes are used. It is necessary to establish the change in scattered radiation with change of irradiated area so that it can be taken into account to correct the uncertainties in treatment time/Monitor Unit (MU) calculations. van Gasteren et al measured $S_{c, p}$ at depth of $5 \mathrm{~cm}$ for photon beams with a quality index (QI) up to and including 0.75 and at depth of $10 \mathrm{~cm}$ with QI larger than 0.75 in order to exclude the influence of contaminant electrons. ${ }^{[1,16,17]}$ Sjögren et al recommended $10 \mathrm{~cm}$ as both reference and normalization depth for all megavoltage photon beam qualities, i.e. ${ }^{60} \mathrm{Co}$ and X-rays accelerators up to $50 \mathrm{MV} .{ }^{[18]}$ ESTRO (European Society for Radiotherapy and Oncology) and AAPM (American Association of Physicists in Medicine) Task group report 74 recommends that CEE should be measured at $10 \mathrm{~g} / \mathrm{cm}^{2}$ depth to avoid electron contamination and the diameter of the phantom should be at least $4 \mathrm{~g} / \mathrm{cm}^{2}$ to achieve lateral electronic equilibrium. ${ }^{[14,19]}$ Till date, the CEE of Bhabhatron -II TAW (telecobalt unit) and Varian Trilogy (linear accelerator unit) has not been reported. In this study, we have investigated the CEE for Bhabhatron -II TAW and Varian Trilogy using a indigenously designed mini phantom.

\section{MATERIALS AND METHOD:}

The study was carried out in two megavoltage teletherapy units. One of the teletherapy machines was Bhabhatron-II TAW Telecobalt machine (Panacea Medical Technologies, Bangalore, India) and the other was Varian Trilogy Linear 
Accelerator (Varian Medical Systems, Palo Alto, California, United States).

The Bhabhatron-II TAW telecobalt unit has a radioisotope (Co60) loaded with average gamma photon energy of $1.25 \mathrm{MeV}$. The secondary collimator of this machine defines field sizes from $(0 \times 0) \mathrm{cm}^{2}$ to $(35 \times 35) \mathrm{cm}^{2}$ at $80 \mathrm{~cm} \mathrm{SSD}$. The secondary collimator consists of a pair of asymmetric Y-jaws (Y1 \& Y2) and a pair of symmetric X-jaws (X1\& X2). Each pair of jaws is parallel, square and symmetrical about the collimator axis of rotation. The distance of the lower surface of X-jaw and Y-jaw from the source are $44.52 \mathrm{~cm}$ and $37.02 \mathrm{~cm}$ respectively. Below both these jaws trimmers are attached.

The Varian Trilogy linear accelerator used in the study has two photon energies, 6MV and 15MV. The collimator system of the unit comprises of two pairs of jaws - Y jaw being the upper jaw and $\mathrm{X}$ jaw is the lower jaw with a tertiary multileaf collimator (MLC) below the jaws. The field size can be varied from $(0.5 \times 0.5) \mathrm{cm}^{2}$ to $(40 \times 40) \mathrm{cm}^{2}$ as measured at $100 \mathrm{~cm}$ target to surface distance (TSD). It has 60 pairs of Millennium MLC leaves. The central $20 \mathrm{~cm}$ have $5 \mathrm{~mm}$ leaf width and outer 20 $\mathrm{cm}$ have $10 \mathrm{~mm}$ leaf width at isocentre.

The collimator scatter factor $\left(\mathrm{S}_{\mathrm{c}}\right)$ is defined as the ratio of dose rate in a mini phantom for a given field size to that of a reference field size $(10 \mathrm{~cm} \times 10 \mathrm{~cm})$ and it counts the in air variation of output with the variation of field size of megavoltage photon beam. ${ }^{[9]}$ The study was done to find the collimator scatter factor for open rectangular fields in Linear Accelerator (Varian Trilogy) for 6MV and 15MV photon beams and in Bhabhatron-II TAW (Telecobalt unit) Co-60 gamma beam at 5 and $10 \mathrm{gm} / \mathrm{cm}^{2}$ depths. To measure the collimator scatter factor $\left(\mathrm{S}_{\mathrm{c}}\right)$, a calibrated $0.125 \mathrm{cc}$ ion chamber (Make: PTW Freiburg Model: 31010 Semiflex) along with PC Electrometer (Sun Nuclear Corporation) and indigenously designed cylindrical wax mini phantom was used. The chamber has nominal response of $3.3 \mathrm{nC} / \mathrm{Gy}$ and long term stability of $\leq 1 \%$ per year. The dimension of the wax miniphantom was as per ESTRO recommendation. ${ }^{[14]}$ The miniphantom was prepared using dental wax of density 0.85 $\mathrm{gm} / \mathrm{cm}^{3}$. The dental wax sheets were melted and fabricated in cylindrical shape with diameter $4 \mathrm{gm} / \mathrm{cm}^{2}$. The chamber slot was made to mimic the jig of any commercially available water phantom such that the distance from the surface of the phantom to its centre is $5 \mathrm{gm} / \mathrm{cm}^{2}$. The centre of the active volume of the ion chamber in the jig was determined in the Computed Tomography (CT) simulator. The CT number for the phantom ranged from -90 to $-105 \mathrm{HU}$. The phantom thickness beyond the centre of the chamber slot was kept $5 \mathrm{gm} / \mathrm{cm}^{2}$ inclusive of the base of the phantom. A buildup of another $5 \mathrm{gm} / \mathrm{cm}^{2}$ height was made in the same design for performing measurement at $10 \mathrm{gm} / \mathrm{cm}^{2}$ depth.

For all the measurements, the long axis of the ion chamber was set parallel to the gantry axis of rotation in such a way that the central axis of the beam passes through the centre of the active volume of the chamber. Six sets of data were collected, two each for $6 \mathrm{MV}$ and $15 \mathrm{MV}$ photon beams and two for Co-60 photon beam. The measurements were carried out at two depths $-5 \mathrm{gm} / \mathrm{cm}^{2}$ and at $10 \mathrm{gm} / \mathrm{cm}^{2}$ for all the energies. Three sets of electrometer readings were recorded delivering 100MU for a reference field size $(10 \times 10) \mathrm{cm}^{2}$ at $5 \mathrm{gm} / \mathrm{cm}^{2}$ depth using $6 \mathrm{MV}$ photon beam.

First, reference square field size $\left(10 \times 10 \mathrm{~cm}^{2}\right)$ was opened and the ion chamber was irradiated at the depth of $5 \mathrm{gm} / \mathrm{cm}^{2}$ for 100 MU using the 6MV photon beam and the three sets of electrometer readings were recorded. Then X-jaw of the secondary collimator was fixed at $5 \mathrm{~cm}$ and the Y-jaw was varied from $5 \mathrm{~cm}$ to $35 \mathrm{~cm}$. For each field size the chamber was irradiated for $100 \mathrm{MU}$ and the electrometer readings were recorded. In the next step the Y-jaw was fixed at $5 \mathrm{~cm}$ while the $\mathrm{X}$-jaw was varied from $5 \mathrm{~cm}$ to $35 \mathrm{~cm}$ and the electrometer readings were recorded. The same procedure was repeated at depth of $10 \mathrm{gm} / \mathrm{cm}^{2}$, by putting additional buildup thickness of $5 \mathrm{gm} / \mathrm{cm}^{2}$.

Measurements of $\mathrm{S}_{\mathrm{c}}$ for $15 \mathrm{MV}$ photon beam were carried out repeating the above steps. For Co-60 beam, the same procedure was repeated keeping source to chamber distance (SCD) $80 \mathrm{~cm}$ and chamber was irradiated for 0.50 minute for all the measurements. Three sets of electrometer reading were noted for the irradiation of each field sizes and the average was taken for calculation. $\mathrm{S}_{\mathrm{c}}$ values for different rectangular fields were then calculated from these data sets and the CEE at two depths $\left(5 \mathrm{gm} / \mathrm{cm}^{2}\right.$ and $\left.10 \mathrm{gm} / \mathrm{cm}^{2}\right)$ for the $6 \mathrm{MV}$ and $15 \mathrm{MV}$ photon and Co-60 gamma beam were calculated.

\section{RESULTS:}

The variation of $\mathrm{S}_{\mathrm{c}}$ with longer side of the rectangular field for the different beam qualities are shown in the figurel, figure2 and figure3. Table 1, Table 2 and Table 3 represent the values of collimator scatter factor for $1.25 \mathrm{MeV}$ Co-60, $6 \mathrm{MV}$ and 15 MV photon beams respectively. $S_{c}(X, Y)$ represents the values of $\mathrm{S}_{\mathrm{c}}$ when the $\mathrm{X}$-jaw was kept fixed at $5 \mathrm{~cm}$ at isocenter and $\mathrm{Y}$ jaw was varied from $5 \mathrm{~cm}$ to $35 \mathrm{~cm}$. While $S_{c}(Y, X)$ represents the values of $S_{c}$ when $Y$-jaw was kept fixed at $5 \mathrm{~cm}$ at isocenter and the $\mathrm{X}$-jaw was varied from $5 \mathrm{~cm}$ to $35 \mathrm{~cm}$. The figures $1-3$ represent the variations of $S_{c}$ with the longer side of the rectangular field at the depth of 5 and $10 \mathrm{gm} / \mathrm{cm}^{2}$ for Co-60 beam, $6 \mathrm{MV}$ and $15 \mathrm{MV}$ photon beams respectively. Results from the tables and graphs show that the values of $S_{c}$ for the rectangular fields as alternatively defined by $\mathrm{X} \& \mathrm{Y}$ jaws are different for high energy photon beams. This indicates that the secondary collimator of Bhabhatron-II TAW and Varian Trilogy units exhibits collimator exchange effect (CEE). The maximum percentage difference between the $S_{c}$ of the corresponding collimator settings for the Bhabhatron-II TAW unit for depths $5 \mathrm{gm} / \mathrm{cm}^{2}$ and $10 \mathrm{gm} / \mathrm{cm}^{2}$ are found to be $0.42 \%$ and $0.5 \%$ respectively.

$\mathrm{S}_{\mathrm{c}}$ values for $6 \mathrm{MV}$ and $15 \mathrm{MV}$ photon beams were found to be higher when Y-jaw (upper jaw) acts as the longer side of the rectangular field. The $S_{c}$ values initially increase with increasing field size but plateau off for larger field sizes. The difference in $\mathrm{S}_{\mathrm{c}}$ values between the two corresponding rectangular fields also increases as the ratio of length to width of the rectangular fields increases. The maximum percentage difference between the $S_{c}$ values of the corresponding collimator settings for $6 \mathrm{MV}$ photon beam from Varian Trilogy at depths $5 \mathrm{gm} / \mathrm{cm}^{2}$ and $10 \mathrm{gm} / \mathrm{cm}^{2}$ are $2.74 \%$ and $2.87 \%$ respectively. For $15 \mathrm{MV}$ photon beam the differences are $3 \%$ and $2.99 \%$ for $5 \mathrm{gm} / \mathrm{cm}^{2}$ and $10 \mathrm{gm} / \mathrm{cm}^{2}$ depth respectively.

\section{DISCUSSION:}

In this study, CEE of Bhabhatron-II TAW and Varian Trilogy photon beams were determined. The measurements were done using an indigenously designed mini-phantom at 5 and $10 \mathrm{gm} / \mathrm{cm}^{2}$ depths for $1.25 \mathrm{MeV}, 6 \mathrm{MV}$ and $15 \mathrm{MV}$ photons. The CEE of Bhabhatron-II TAW at depth 5 and $10 \mathrm{gm} / \mathrm{cm}^{2}$ was within $0.5 \%$ in this study. Senthilkumar et al found the CEE of Theratron Phoenix Co-60 Teletherapy machine to be less than $0.5 \%$ using two mini-phantoms (PMMA and Bee's Wax). ${ }^{[10]}$ ESTRO (Booklet No. 6) mentioned CEE for cobalt unit (MDS Nordion Theratron $780,{ }^{60} \mathrm{Co}$ ) of about $0.5 \%$. ${ }^{[15]}$ Therefore, the CEE of Bhabhatron-II TAW can be ignored during clinical dosimetry.

The CEE of Varian Trilogy for $6 \mathrm{MV}$ photon beams at $5 \mathrm{gm} / \mathrm{cm}^{2}$ depth was $2.74 \%$ and at $10 \mathrm{gm} / \mathrm{cm}^{2}$ depth was $2.87 \%$. The CEE for $15 \mathrm{MV}$ photon beams at $5 \mathrm{gm} / \mathrm{cm}^{2}$ depth was found to be $3 \%$ and at $10 \mathrm{gm} / \mathrm{cm}^{2}$ depth it was $2.99 \%$. These results indicate that Varian Trilogy exhibits CEE when using 6MV and 15MV 
photon beams. Murugan Appasamy et al reported the CEE for 6MV photon beams of Elekta Synergy and Siemens Primus Linear Accelerator to be $0.85 \%$ and $1.6 \%$ respectively using a columnar mini-phantom. ${ }^{[1]}$ Sudhir Kumar et al also reported CEE of $1.66 \%, 1.44 \%$ and $1.19 \%$ for $1.5 \mathrm{~cm}, 5.0 \mathrm{~cm}$ and $10 \mathrm{~cm}$ depths respectively using 6MV photon beam in Siemens Primus Linear Accelerator. ${ }^{[9]}$ For 15 MV photon beams, they found CEE of $1.74 \%$ and $1.38 \%$ at $3 \mathrm{~cm}$ and $10 \mathrm{~cm}$ depths respectively. ESTRO (Booklet No. 6) mentioned CEE of $1 \%$ for the EOS SL20 (MLC) using 18MV photon beam and $2.4 \%$ for the Siemens Primus (MLC) using 6MV photon beams. ${ }^{[15]}$

We also found that the value of $\mathrm{S}_{\mathrm{C}}$ for rectangular fields when the longer side is defined by Y-jaws are higher than the corresponding rectangular field when the longer side is defined by $\mathrm{X}$-jaws. The difference in $\mathrm{S}_{\mathrm{C}}$ values between the two corresponding rectangular fields gradually increases as the elongation ratio of rectangular field increases. The reason for CEE of the Varian Trilogy collimator system therefore can be attributed to the backscattered radiation to the monitor chamber by the Y-jaws (upper jaws) of the secondary collimator.

\section{CONCLUSION:}

This study further confirms the CEE of megavoltage teletherapy machines used in clinics. The CEE of Cobalt Teletherapy units can be ignored in clinical dosimetry. However, the CEE of Linear Accelerators having energies 6 MV \& $15 \mathrm{MV}$ should be taken into consideration during clinical dosimetry. This study found that CEE for $15 \mathrm{MV}$ photon beam has minimal difference at $5 \mathrm{gm} / \mathrm{cm}^{2}$ and $10 \mathrm{gm} / \mathrm{cm}^{2}$ depths of measurement. Therefore, a two dimensional table of Collimator Scatter Factor should be generated for rectangular fields during MU calculations in Linear Accelerators. For TPS based calculations the generated data should be incorporated during beam modeling for accurate dose delivery in clinical dosimetry.

TABLE 1 :Collimator Scatter Factor $\left(S_{c}\right)$ of Co-60 beam at 5 an d $10 \mathrm{gm} / \mathrm{cm}^{2}$ depths.

\begin{tabular}{|c|c|c|c|c|c|c|}
\hline \multicolumn{7}{|c|}{${ }^{60} \mathrm{Co}$, Bhabhatron-II TAW } \\
\hline \multirow[t]{2}{*}{ Longer side of the field $(\mathrm{cm})$} & \multicolumn{3}{|c|}{ Depth $=5 \mathrm{gm} / \mathrm{cm}^{2}$} & \multicolumn{3}{|c|}{ Depth $=10 \mathrm{gm} / \mathrm{cm}^{2}$} \\
\hline & $\mathrm{S}_{\mathrm{C}}(\mathrm{X}, \mathrm{Y})$ & $\mathrm{S}_{\mathrm{C}}(\mathrm{Y}, \mathrm{X})$ & Difference (\%) & $\mathrm{S}_{\mathrm{C}}(\mathrm{X}, \mathrm{Y})$ & $\mathrm{S}_{\mathrm{C}}(\mathrm{Y}, \mathrm{X})$ & Difference (\%) \\
\hline 5 & 0.94671 & 0.94671 & 0.00 & 0.94714 & 0.94714 & 0.00 \\
\hline 6 & 0.95830 & 0.95978 & 0.15 & 0.95892 & 0.96235 & 0.36 \\
\hline 7 & 0.96644 & 0.96842 & 0.20 & 0.96648 & 0.96898 & 0.26 \\
\hline 8 & 0.96768 & 0.97261 & 0.51 & 0.97024 & 0.97211 & 0.19 \\
\hline 9 & 0.97261 & 0.97409 & 0.15 & 0.97141 & 0.97580 & 0.45 \\
\hline 10 & 0.97508 & 0.97533 & 0.03 & 0.97464 & 0.97793 & 0.34 \\
\hline 11 & 0.97730 & 0.97681 & 0.05 & 0.97733 & 0.97797 & 0.06 \\
\hline 12 & 0.97755 & 0.97853 & 0.10 & 0.97773 & 0.98043 & 0.28 \\
\hline 13 & 0.97903 & 0.98224 & 0.33 & 0.98199 & 0.98416 & 0.22 \\
\hline 14 & 0.98100 & 0.98248 & 0.15 & 0.98186 & 0.98576 & 0.40 \\
\hline 15 & 0.98248 & 0.98544 & 0.30 & 0.98363 & 0.98679 & 0.32 \\
\hline 16 & 0.98520 & 0.98470 & 0.05 & 0.98722 & 0.98722 & 0.00 \\
\hline 17 & 0.98544 & 0.98495 & 0.05 & 0.98519 & 0.98775 & 0.26 \\
\hline 18 & 0.98840 & 0.98569 & 0.28 & 0.98715 & 0.98922 & 0.21 \\
\hline 19 & 0.98865 & 0.98544 & 0.33 & 0.98869 & 0.98948 & 0.08 \\
\hline 20 & 0.99062 & 0.98692 & 0.37 & 0.99045 & 0.99155 & 0.11 \\
\hline 22 & 0.99087 & 0.98766 & 0.32 & 0.99158 & 0.99075 & 0.08 \\
\hline 24 & 0.99161 & 0.98890 & 0.27 & 0.99248 & 0.99388 & 0.14 \\
\hline 26 & 0.99087 & 0.99062 & 0.02 & 0.99451 & 0.99318 & 0.13 \\
\hline 28 & 0.99210 & 0.98840 & 0.37 & 0.99321 & 0.99401 & 0.08 \\
\hline 30 & 0.99334 & 0.98865 & 0.47 & 0.99554 & 0.99378 & 0.18 \\
\hline 32 & 0.99433 & 0.98964 & 0.47 & 0.99488 & 0.99135 & 0.36 \\
\hline 35 & 0.99358 & 0.98939 & 0.42 & 0.99647 & 0.99151 & 0.50 \\
\hline
\end{tabular}

TABLE 2 : Collimator Scatter Factor $\left(S_{c}\right)$ of $6 \mathrm{MV}$ at 5 and $10 \mathrm{gm} / \mathrm{cm}^{2}$ depths.

\begin{tabular}{|c|c|c|c|c|c|c|}
\hline \multicolumn{7}{|c|}{ Varian Trilogy (6 MV) } \\
\hline \multirow{2}{*}{$\begin{array}{l}\text { Longer side of } \\
\text { the field }(\mathrm{cm})\end{array}$} & \multicolumn{3}{|c|}{ Depth $=5 \mathrm{gm} / \mathrm{cm}^{2}$} & \multicolumn{3}{|c|}{ Depth $=10 \mathrm{gm} / \mathrm{cm}^{2}$} \\
\hline & $\mathrm{S}_{\mathrm{C}}(\mathrm{X}, \mathrm{Y})$ & $\mathrm{S}_{\mathrm{C}}(\mathrm{Y}, \mathrm{X})$ & Difference (\%) & $\mathrm{S}_{\mathrm{C}}(\mathrm{X}, \mathrm{Y})$ & $\mathrm{S}_{\mathrm{C}}(\mathrm{Y}, \mathrm{X})$ & Difference (\%) \\
\hline 5 & 0.96357 & 0.96357 & 0.00 & 0.96309 & 0.96309 & 0.00 \\
\hline 6 & 0.97002 & 0.97387 & 0.01 & 0.97022 & 0.96659 & 0.38 \\
\hline 7 & 0.97477 & 0.97715 & 0.06 & 0.97484 & 0.96911 & 0.59 \\
\hline 8 & 0.97930 & 0.97896 & 0.03 & 0.97861 & 0.97036 & 0.85 \\
\hline 9 & 0.98246 & 0.98043 & 0.21 & 0.98155 & 0.97190 & 0.99 \\
\hline 10 & 0.98620 & 0.98122 & 0.51 & 0.98420 & 0.97204 & 1.25 \\
\hline 11 & 0.98823 & 0.98190 & 0.65 & 0.98658 & 0.97316 & 1.38 \\
\hline 12 & 0.99072 & 0.98269 & 0.82 & 0.98854 & 0.97456 & 1.43 \\
\hline 13 & 0.99310 & 0.98394 & 0.93 & 0.98966 & 0.97400 & 1.61 \\
\hline 14 & 0.99468 & 0.98394 & 1.09 & 0.99063 & 0.97442 & 1.66 \\
\hline 15 & 0.99593 & 0.98461 & 1.15 & 0.99287 & 0.97512 & 1.82 \\
\hline 16 & 0.99796 & 0.98518 & 1.30 & 0.99413 & 0.97484 & 1.98 \\
\hline 17 & 1.00000 & 0.98484 & 1.54 & 0.99483 & 0.97484 & 2.05 \\
\hline 18 & 1.00113 & 0.98541 & 1.60 & 0.99567 & 0.97568 & 2.05 \\
\hline 19 & 1.00215 & 0.98518 & 1.72 & 0.99623 & 0.97540 & 2.14 \\
\hline 20 & 1.00328 & 0.98631 & 1.72 & 0.99916 & 0.97498 & 2.48 \\
\hline 22 & 1.00532 & 0.98654 & 1.90 & 1.00042 & 0.97526 & 2.58 \\
\hline 24 & 1.00701 & 0.98654 & 2.08 & 1.00042 & 0.97568 & 2.54 \\
\hline
\end{tabular}




\begin{tabular}{|l|l|l|l|l|l|l|l|}
\hline 26 & 1.00803 & 0.98665 & 2.17 & 1.00112 & 0.97610 & 2.56 \\
\hline 28 & 1.00984 & 0.98665 & 2.35 & 1.00210 & 0.97665 & 2.61 \\
\hline 30 & 1.01142 & 0.98688 & 2.49 & 1.00420 & 0.97749 & 2.73 \\
\hline 32 & 1.01301 & 0.98778 & 2.55 & 1.00559 & 0.97777 & 2.85 \\
\hline 35 & 1.01493 & 0.98789 & 2.74 & 1.00713 & 0.97903 & 2.87 \\
\hline
\end{tabular}

TABLE 3 : Collimator Scatter Factor $\left(S_{c}\right)$ of $15 \mathrm{MV}$ at 5 and $10 \mathrm{gm} / \mathrm{cm}^{2}$ depths.

\begin{tabular}{|c|c|c|c|c|c|c|}
\hline \multicolumn{7}{|c|}{ Varian Trilogy (15 MV) } \\
\hline \multirow{2}{*}{ Longer side of the field $(\mathrm{cm})$} & \multicolumn{3}{|c|}{ Depth $=5 \mathrm{gm} / \mathrm{cm}^{2}$} & \multicolumn{3}{|c|}{ Depth $=10 \mathrm{gm} / \mathrm{cm}^{2}$} \\
\hline & $\mathrm{S}_{\mathrm{C}}(\mathrm{X}, \mathrm{Y})$ & $\mathrm{S}_{\mathrm{C}}(\mathrm{Y}, \mathrm{X})$ & Difference (\%) & $\mathrm{S}_{\mathrm{C}}(\mathrm{X}, \mathrm{Y})$ & $\mathrm{S}_{\mathrm{C}}(\mathrm{Y}, \mathrm{X})$ & Difference (\%) \\
\hline 5 & 0.97029 & 0.97029 & 0.00 & 0.97038 & 0.97038 & 0.00 \\
\hline 6 & 0.97581 & 0.97350 & 0.24 & 0.97668 & 0.97353 & 0.32 \\
\hline 7 & 0.97952 & 0.97511 & 0.45 & 0.98041 & 0.97574 & 0.48 \\
\hline 8 & 0.98364 & 0.97722 & 0.66 & 0.98402 & 0.97644 & 0.78 \\
\hline 9 & 0.98605 & 0.97742 & 0.88 & 0.98647 & 0.97738 & 0.93 \\
\hline 10 & 0.98866 & 0.97812 & 1.08 & 0.98881 & 0.97796 & 1.11 \\
\hline 11 & 0.99006 & 0.97842 & 1.19 & 0.99032 & 0.97843 & 1.22 \\
\hline 12 & 0.99167 & 0.97852 & 1.34 & 0.99207 & 0.97878 & 1.36 \\
\hline 13 & 0.99338 & 0.97942 & 1.42 & 0.99324 & 0.97866 & 1.49 \\
\hline 14 & 0.99438 & 0.97932 & 1.54 & 0.99440 & 0.97913 & 1.56 \\
\hline 15 & 0.99528 & 0.97983 & 1.58 & 0.99522 & 0.97948 & 1.61 \\
\hline 16 & 0.99588 & 0.97983 & 1.64 & 0.99662 & 0.97983 & 1.71 \\
\hline 17 & 0.99689 & 0.97993 & 1.73 & 0.99709 & 0.97971 & 1.77 \\
\hline 18 & 0.99759 & 0.98003 & 1.79 & 0.99779 & 0.97983 & 1.83 \\
\hline 19 & 0.99859 & 0.98023 & 1.87 & 0.99860 & 0.98006 & 1.89 \\
\hline 20 & 0.99990 & 0.98033 & 2.00 & 0.99988 & 0.98041 & 1.99 \\
\hline 22 & 1.00171 & 0.98043 & 2.17 & 1.00152 & 0.98064 & 2.13 \\
\hline 24 & 1.00281 & 0.98103 & 2.22 & 1.00268 & 0.98088 & 2.22 \\
\hline 26 & 1.00442 & 0.98093 & 2.39 & 1.00385 & 0.98111 & 2.32 \\
\hline 28 & 1.00582 & 0.98113 & 2.52 & 1.00525 & 0.98134 & 2.44 \\
\hline 30 & 1.00773 & 0.98173 & 2.65 & 1.00700 & 0.98123 & 2.63 \\
\hline 32 & 1.00883 & 0.98173 & 2.76 & 1.00921 & 0.98193 & 2.78 \\
\hline 35 & 1.01154 & 0.98203 & 3.00 & 1.01096 & 0.98158 & 2.99 \\
\hline
\end{tabular}

\section{REFERENCES}

1. van Gasteren J, Heukelom S, van Kleffens H, van der Laarse R, Venselaar J, Westermann $\mathrm{C}$. The determination of phantom and collimator scatter components of the output of megavoltage photon beams: measurement of the collimator scatter part with a beam-coaxial narrow cylindrical phantom. Radiotherapy and Oncology. 1991;20(4):250-257.

2. Holt J, Laughlin J, Moroney J. The Extension of the Concept of Tissue-Air Ratios (TAR) to High-Energy X-Ray Beams. Radiology. 1970;96(2):437-446.

3. Khan F, Sewchand W, Lee J, Williamson J. Revision of tissue-maximum ratio and scatter-maximum ratio concepts for cobalt 60 and higher energy $x$-ray beams. Medical Physics. 1980;7(3):230-237.

4. Spicka J, Herron D, Orton C. Separating Output Factor into Collimator Factor and Phantom Scatter Factor for Megavoltage Photon Calculations. Medical Dosimetry. 1988;13(1):23-24.

5. Luxton G, Astrahan M. Output factor constituents of a high-energy photon beam. Medical Physics. 1988;15(1):88-91.

6. Kase K, Svensson G. Head scatter data for several linear accelerators (4-18 MV). Medical Physics. 1986; 13(4):530-532.

7. Higgins P, Sohn W, Sibata C, McCarthy W. Scatter factor corrections for elongated fields. Medical Physics. 1989;16(5):800-802

8. Tatcher $M$, Bjarngard $B$. Head-scatter factors in rectangular photon fields. Medical Physics. 1993;20(1):205-206.

9. Kumar Sudhir, Sharma S.D., Tripathi U.B., Goswami B.C., and Bhatt B.C Collimator exchange effect of a multileaf collimator system. Journal of Medical Physics. 2003; 28(1): 12-17.

10. Senthilkumar $\mathrm{S}$, Ramakrishnan V. Design of mini phantom and measurement of cobalt-60 beam data parameters. Journal of Medical Physics. 2008;33(3):100.

11. Appasamy M, Xavier S, Kuppusamy T, Velayudham R. Measurement of Head Scatter Factor for Linear Accelerators using Indigenously Designed Columnar Mini Phantom. Polish Journal of Medical Physics And Engineering. $2011 ; 17(1)$

12. Ahnesjö A, Knöös T, Montelius A. Application of the convolution method for calculation of output factors for therapy photon beams. Medical Physics. 1992:19(2):295-301.

13. Lam $\mathrm{K}$, Ten Haken R. In phantom determination of collimator scatter factor. Medical Physics. 1996;23(7):1207-1212.

14. Dutreix A., Bjärngard B.E., Bridier A., Mijnheer B., Shaw J.E. and Svensson H. Monitor unit calculation for high energy photon beams. ESTRO Booklet 3, Garant ed., Leuven, 1997.

15. Mijnheer B, Bridier A, Garibaldi C. Monitor Unit Calculation for High Energy Photon Beams - Practical Examples ESTRO Booklet No:6, Brussels, Belgium: 2001

16. Nilsson B. Electron contamination from different materials in high energy photon beams. Physics in Medicine and Biology. 1985:30(2):139-151.

17. Sjögren R, Karlsson M. Electron contamination in clinical high energy photon beams. Medical Physics. 1996;23(11):1873-1881.

18. Sjögren R, Karlsson M, Karlsson M, Svensson H. Depth for dose calibration in high energy photon beams. Radiotherapy and Oncology. 1997:43(3):311-313.
19. Zhu TC, Ahnesjö A, Lam KL, et al. Report of AAPM Therapy Physics Committee Task Group 74: in-air output ratio, Sc, for megavoltage photon beams. Med Phys. 2009;36(11):5261-5291. 